\title{
Never let a serious crisis go to waste: the introduction of supplemental carbon taxes in Europe
}

\author{
Fabio Bothner ${ }^{1 \star}$ (D), Svenja Marie Schrader ${ }^{1}$, Frank Bandau ${ }^{1}$ (D) and Nicole Holzhauser ${ }^{2}$ (D) \\ ${ }^{1}$ Institute of Political Science, University of Bamberg, Feldkirchenstraße 21, 96045 Bamberg, Germany and \\ ${ }^{2}$ Institute of Sociology, Technische Universität Braunschweig, Bienroder Weg 97, 38108 Braunschweig, \\ Germany. \\ ${ }^{*}$ Corresponding author: E-mail: fabio.bothner@uni-bamberg.de
}

(Received 8 January 2021; revised 29 July 2021; accepted 31 August 2021; first published online 31 January 2022)

\begin{abstract}
The literature on carbon pricing offers competing explanations for the introduction of carbon taxation. This article contributes to the field by highlighting the interaction of dynamic political factors and external pressures in explaining the timing of the adoption of carbon taxes. Focusing on the second wave of European countries, the study combines the multiple streams framework with qualitative comparative analysis to identify conditions favourable to the introduction of carbon taxes. Additional case studies on Ireland and Portugal serve to illuminate the reform process, especially the role of policy entrepreneurs. This approach yields three insights. First, fiscal crises provide political actors with an opportunity to raise environmental taxes. Second, the introduction of carbon taxation is most likely when push and pull factors come together, i.e. when high problem pressure coincides with governments receptive to environmental issues. Finally, the prospects of "green" policy entrepreneurs are strongly determined by their standing within the government.
\end{abstract}

Keywords: Carbon tax; climate policy; Ireland; multiple streams; Portugal; QCA

\section{Introduction}

Regulatory efforts to fight climate change by carbon pricing come mainly in two forms, carbon taxes and emission trading. Often seen as competing approaches to reducing emissions, the environmental and economic implications of both the instruments have been widely discussed in the literature (e.g. Andersen 2009; Speck 2013; Haites 2018). In addition, there is a substantial literature on the political and economic determinants of carbon pricing which is dominated by studies which either highlight international factors such as policy diffusion and the role of international organisations (Thisted and Thisted 2019; Steinebach et al., 2021) or offer in-depth accounts of policy adoption on the national level or, as in the case of the European Emission Trading System

(c) The Author(s), 2022. Published by Cambridge University Press. This is an Open Access article, distributed under the terms of the Creative Commons Attribution licence (http://creativecommons.org/licenses/by/4.0/), which permits unrestricted re-use, distribution and reproduction, provided the original article is properly cited. 
(EU ETS), the supranational level (e.g. Sterner 1994; Kasa 2000; Sairinen 2003; Convery 2009; Sénit 2012; Convery et al. 2013; Ryan and Micozzi, 2021).

Focusing on the politics of carbon taxation in Europe, we contribute to the limited but growing literature taking a comparative perspective (Harrison 2010; Andersen 2019; Skovgaard et al. 2019). Thus far, research has focused on the question why some countries introduce carbon taxes and why others refrain from doing so, i.e. which factors support or impede the choice of this policy instrument. On the national level, economic, political, and institutional determinants can be distinguished. Concerning domestic institutions, existing research shows that parliamentary systems with proportional representation and neo-corporatist policy structures provide a favourable context for the introduction of carbon taxes (Harrison 2010; Andersen 2019). Proportional electoral systems in turn facilitate access to government for green parties, which are seen as important political actors pushing for carbon taxes (Andersen 2019, 1097). Finally, Skovgaard et al. (2019) highlight the importance of the economic context by showing that fiscal and economic crises at times contributed to the adoption of carbon pricing, including carbon taxes.

This article contributes to the literature by highlighting the interaction of political factors and external pressures in explaining the timing of policy adoption. Given this interest in the timing of policies, our analysis focuses on dynamic political and socio-economic context factors, such as government partisanship and fiscal pressure, as well as the role of policy entrepreneurs. ${ }^{1}$ While existing research has mainly concentrated on the Nordic pioneers (Sterner 1994; Kasa 2000; Sairinen 2003), we focus on six West European countries (France, Iceland, Ireland, Portugal, Spain, and the UK) which introduced carbon taxation while already participating in the EU ETS. To answer the question of why those countries introduced supplemental carbon taxes at the time they did, we apply the multiple streams framework (MSF) which is well suited to investigate the timing of policies (Kingdon 1995; Zahariadis 2003). In contrast to previous research in the field which applies the MSF to single cases or a small number of cases (e.g. Keskitalo et al. 2012; Cooper-Searle et al. 2018; Ryan and Micozzi 2021), we combine qualitative comparative analysis (QCA) and case studies. We are thus able to offer more general insights concerning favourable context conditions for the adoption of carbon taxes as well as insights on how favourable and unfavourable conditions affect the efforts of policy entrepreneurs in practice.

The article is structured as follows: we first provide an overview of the emergence of carbon taxation in Europe. Next, the MSF is applied to the policy subfield of carbon taxation. After outlining the research design, we then conduct the empirical analysis which consists of two parts, the QCA covering all six countries and two case studies on Ireland and Portugal. In the conclusion, we summarise our findings, connect them to the literature in the field and discuss strengths and limitations of our methodological approach.

\section{The emergence of carbon taxation in Europe}

To put a price on carbon to internalise the external costs of climate, unfriendly behaviour is neither a radical nor a new idea. In fact, the original idea of a carbon 
Table 1. Carbon taxes in Europe

\begin{tabular}{lcccc}
\hline Country & $\begin{array}{c}\text { Year of adoption/ } \\
\text { implementation }\end{array}$ & $\begin{array}{c}\text { Part of EU ETS by } \\
\text { time of adoption }\end{array}$ & $\begin{array}{c}\text { Price November } \\
\text { 2019 in US\$/tCO }\end{array}$ & $\begin{array}{c}\text { Share of jurisdiction's } \\
\text { emissions covered } \\
\text { (in percent) }\end{array}$ \\
\hline Finland & $1989 / 1990$ & No & $58.50 / 68.43$ & 36.36 \\
Poland & $1989 / 1990$ & No & 0.08 & 3.74 \\
Norway & $1990 / 1991$ & No & $3.26 / 57.14$ & 61.81 \\
Sweden & $1990 / 1991$ & No & 121.29 & 39.61 \\
Denmark & $1991 / 1992$ & No & $22.17 / 25.91$ & 39.98 \\
Slovenia & $1996 / 1997$ & No & 19.09 & 23.61 \\
Estonia & $1999 / 2000$ & No & 2.21 & 3.3 \\
Latvia & $2003 / 2004$ & No & 4.97 & 14.68 \\
Liechtenstein & $2007 / 2008$ & Yes & 96.57 & 26.0 \\
Switzerland & $2007 / 2008$ & No & 96.57 & 33.29 \\
Iceland & $2009 / 2010$ & Yes & 31.30 & 26.57 \\
Ireland & $2009 / 2010$ & Yes & 22.07 & 49.66 \\
UK & $2011 / 2013$ & Yes & 21.79 & 23.28 \\
France & $2013 / 2014$ & Yes & 49.23 & 35.2 \\
Spain & $2013 / 2014$ & Yes & 16.56 & 2.51 \\
Portugal & $2014 / 2015$ & Yes & 14.06 & 28.5 \\
\hline
\end{tabular}

Note: Finland, Norway, and Denmark do not have one carbon price for all emissions. While Finland differentiates between transport (higher price) and other fuels (lower price), Denmark has separate prices for fossil fuels (higher price) and F-gases (lower price). Norway uses different tax rates for different industries, with emission-intensive industries having to pay a lower fee.

Source: World Bank (2019).

tax was introduced more than 30 years ago, at the International Conference of the Changing Atmosphere in Toronto (Andersen 2019, 1084). Subsequently, European countries established themselves as frontrunners in carbon taxation (Speck 2013, 172-174). In 1990, Finland was the first country to introduce a carbon tax by putting a price on the $\mathrm{CO}_{2}$ emissions of fuels. Poland, Norway, Sweden, and Denmark followed suit and implemented carbon taxes in 1990, 1991, and 1992 (World Bank $2019,14)$. After the Rio Earth Summit in 1992, the European Commission started an initiative to introduce an EU-wide carbon energy tax (Padilla and Roca 2004, 273274). But those efforts failed due to strong opposition of industrial lobbies which is why the carbon energy tax proposal was formally withdrawn in 1997 (Convery 2009, 392-393). Consequently, the European Commission changed its strategy in the wake of the Kyoto negotiations and pushed for the introduction of emission trading instead of carbon taxation to meet the EU's Kyoto targets (Convery 2009, 398-405). This time, the initiative was successful and resulted in the establishment of the EU ETS in 2005. With the introduction of the EU ETS, it was questionable if further European countries would introduce carbon taxes. However, as Table 1 shows, this was the case as Iceland, Ireland, the UK, France, Spain, and Portugal introduced national carbon taxes after the launch of the EU ETS. ${ }^{2}$

In accordance with Thisted and Thisted (2019), national carbon pricing in Western Europe can thus be divided into three phases. The first wave (1990-2000) mainly consisting of the Nordic pioneers (Finland, Sweden, Norway, and Denmark), a transition period (2000-2008) characterised by the introduction of an EU-wide pricing system, and finally the second wave covering countries which have introduced carbon taxes 
since 2008. This study concentrates on the six West European "second-wavers" for mainly two reasons. First, previous research has primarily been focused on the Nordic pioneers (see Sterner 1994; Kasa 2000; Sairinen 2003). Second, the situation of pioneers and second wavers is hardly comparable as they adopted carbon taxation under different circumstances. Carbon pricing has over time "transitioned from being a policy employed only by pioneer countries to becoming a global norm" (Thisted and Thisted 2019, 1), i.e. the pressure to introduce national measures to fight climate change has risen considerably. In contrast to the pioneers, second wavers are facing internationally binding emission reduction targets while already participating in the EU ETS, a supranational system to lower carbon emissions.

While all six countries introduced supplemental carbon taxes, we ask what accounts for the exact timing of policy adoption. Given the static nature of institutional features, we assume that dynamic socio-economic and political factors contributed to this result and that the interaction of those dynamic factors proved crucial. To capture the interplay of problem pressure and political factors, we apply the MSF which is presented in the next section.

\section{Applying the MSF to carbon taxation}

The original goal of the MSF, as formulated by John Kingdon, is to answer the question when a policy idea's time has come or, less philosophically, "what makes people in around government attend, at any given time, to some subjects and not to others" (Kingdon 1995, 1). While Kingdon primarily concentrated on agenda setting, other authors later on expanded the MSF to the decision-making process (Zahariadis 2003; Herweg et al. 2015). At the heart of the MSF is the conceptualisation of three streams - problem stream, political stream, and policy stream - which float independently of each other and have to be coupled by policy entrepreneurs in the policy-making process under favourable conditions (Kingdon 1995, 196-208; Herweg et al. 2015; Herweg et al. 2018). Policy changes, such as the introduction of a carbon tax, are supposed to be most likely when the three streams are "ripe" and a policy window available because it is under those conditions that policy entrepreneurs have the best chances to succeed in coupling the three streams. At this point, it is important to note that the MSF is based on a probabilistic logic, i.e. if the conditions are met, policy change becomes more likely but is not guaranteed (Kingdon 1995, 208). Correspondingly, if one or more of those conditions are not met, policy change becomes less likely but cannot be ruled out.

\section{Problem stream}

The problem stream contains the problems which are simultaneously discussed in the political system. But what constitutes a problem? A problem results from the gap between people's perceptions of how things are and how they ought to be. While there are countless potential problems at any given time, only a few succeed in making it to the political agenda. This happens through indicators, focusing events, and feedback from existing programs (Kingdon 1995, 90-115). In our case, two different kinds of indicators are crucial. Thus, while the case for carbon taxation is often made on environmental grounds, we emphasise that fiscal considerations must not be 
neglected. If a country does not meet its climate targets, "environmental pressure" rises to implement countermeasures such as carbon taxation. Similarly, if a country comes under severe fiscal pressure, the introduction of carbon taxes offers an attractive option to generate additional revenues, at least when compared with raising other taxes (Jagers and Hammar 2009, 224-229; Schlegelmilch and Joas 2016). This argument is supported by previous studies which show that not only environmental but also fiscal considerations play an important role in the introduction of carbon taxes (Sterner 1994; Harrison 2010; Speck 2013; Skovgaard et al. 2019). Consequently, we expect the problem stream to be ripe when environmental or fiscal pressure is high.

\section{Political stream}

The political stream focuses on the distribution of power within the political system but also within society. In Kingdon's original analysis of political decisionmaking in the USA, this includes government ideology, organised interests as well as the "national mood" (Kingdon, 1995, 145-164). Given that all countries covered by our analysis represent parliamentary systems, we follow Zahariadis (2003) who argues that, with this system of government, government ideology is supposed to be the crucial factor in the political stream (see also Herweg et al. 2018, 36-37). More precisely, we argue that it is the emphasis governing parties put on environmental issues that matters. Green parties and other green-minded parties in government are more likely to introduce carbon taxation than parties representing conventional growth ideologies (cf. Andersen 2019). Hence, we expect the political stream to be ripe when a green-minded government is in power.

\section{Policy stream}

The policy stream, also described by Kingdon as "the policy primeval soup", contains the ideas that float around in the communities of policy experts. This stream thus contains policy options, such as the introduction of a carbon tax, which at some point might become the solutions to one of the problems present in the problem stream. To do so, proposals have to meet some 'criteria of survival', i.e. they must neither collide with organisational, technical, and legal restrictions (technical feasibility) nor with budget constraints (financial viability), and they have to be in line with general values dominant in the relevant policy community (value acceptability) (Kingdon 1995, 116-144). Since carbon taxes do not generate financial costs but revenues and the implementation of those taxes is, as many countries have proven, technically feasible, the support by policy experts seems to be the main factor concerning the ripeness of the policy stream.

\section{Policy windows}

According to the MSF, policy change results from the successful coupling of the three streams. The precondition for a successful coupling is the opening of a policy window. Policy windows can either open in the problem stream or in the political stream. In the former case, focusing events or changes of indicators can steer 
attention to a problem and thus provide the opportunity to present fitting policy solutions. In the latter case, political changes such as changes of government can offer policy entrepreneurs an opportunity to advance new policy proposals (Kingdon 1995, 173-175; Zahariadis 2003, 66-86). Given its crucial role in the MSF, a policy window in either of the two streams is a necessary condition for the coupling of the streams and policy change.

\section{Policy entrepreneurs}

While ripe streams and an open policy window are the conditions under which policy change becomes likely, policy entrepreneurs are the central actors in the coupling process (Kingdon 1995, 179-183; Herweg et al. 2018, 28-29). Policy entrepreneurs are actors who invest their resources in coupling the three streams in return for "anticipated future gains in form of material, purposive, or solidary benefits" (Kingdon 1995, 179). The chances of success rise when policy entrepreneurs have direct access to policymakers or, even better, when they hold a leadership position within the government (Kingdon 1995, 180-181; Herweg et al. 2015, 445446). Hence, we argue that it is essential that a policy entrepreneur engages in coupling the streams and that the introduction of a carbon tax becomes more likely when a leading member of government, such as the prime minister or the minister of finance, serves as policy entrepreneur.

\section{Research design}

The MSF has thus far mainly been applied to qualitative studies of single cases or a small number of cases (for applications to climate policy see, e.g. Keskitalo et al., 2012; Cooper-Searle et al., 2018; Ryan and Micozzi, 2021). Engler and Herweg (2019) outline the high barriers of entry for medium and large $n$ applications of the MSF, which result from methodological issues as well as data availability. In order to overcome those barriers, we follow three suggestions made by these authors: (1) the choice of a method that corresponds with the framework's research questions, (2) a partial application of the MSF, and (3) the combination of different methods to make use of their various advantages.

Concerning the choice of an appropriate method for applying the MSF to our medium $n$ sample of 16 legislative periods, we opt for QCA. ${ }^{3}$ The main advantage of this method is that it "enables researchers to examine the interplay of individual factors and their combined effect on the outcome much more easily than regression analyses" (Engler and Herweg 2019, 913). This makes QCA the appropriate method to analyse the interaction of socio-economic and political factors in the introduction of supplemental carbon taxes in a medium number of cases. Due to theoretical considerations as well as data availability, we follow the example of the few existing MSF/QCA studies (see Sager and Rielle 2013; Sager and Thomann 2017) and confine the crosscase analysis to a partial application of the MSF by concentrating on four elements: environmental and fiscal pressure in the problem stream, the ripeness of the political stream in terms of government ideology and the availability of a policy window. This restriction is based on the preliminary assumption that the policy stream is supposed to be ripe as carbon pricing has become a global norm. Experts, 
especially climate economists, will generally not oppose but support related reform initiatives (Rabe 2018; Thisted and Thisted 2019).

In accordance with Sager and Thomann (2017), we also exclude policy entrepreneurs from the QCA. This is for methodological as well as theoretical reasons. First, coding the presence or absence of a policy entrepreneur in a convincing way requires substantial qualitative information about the coupling process, which is hard to come by for all 16 cases (cf. Engler and Herweg 2019, 909). But the exclusion of policy entrepreneurs from the QCA can also be justified on theoretical grounds. The goal of the QCA is to reveal the conditions under which carbon taxes were adopted. In contrast, the role of policy entrepreneurs is closely tied to their actual actions under those conditions (see e.g. Harrison, 2010). Analytically, it therefore makes sense to analyse the conditions of policy adoption in the first step and to take a closer look at the coupling activities of potential policy entrepreneurs in the second step. For this purpose, the QCA has to be complemented by process tracing to examine the supposed causal mechanisms (Beach and Rohlfing 2018; Blatter and Haverland 2012, 231-235). We thus supplement the QCA with two case studies, which allow us to focus on the coupling efforts by policy entrepreneurs under favourable as well as unfavourable conditions.

\section{Qualitative comparative analysis}

QCA is based on subset relations and Boolean algebra, aiming at the identification of necessary and sufficient conditions for the occurrence of an outcome (Ragin 2008). Main advantages of QCA are the assumption of conjunctural causality, i.e. the effect of a condition unfolds in combination with other conditions, and the assumption of equifinality, i.e. an outcome results from different mutually nonexclusive explanations (Schneider and Wagemann 2013, 79). Moreover, QCA is particularly well suited for a medium number of cases. There are two main variants of QCA. The original crisp-set QCA (csQCA), which is based on the binary classification of cases $(0=$ not part of a subset, $1=$ part of a subset), can be distinguished from fuzzy-set QCA (fsQCA) that allows for additional values between 0 and 1 (Schneider and Wagemann 2013, 18). Given the inclusion of metric conditions in our analysis, the fsQCA suits our purpose best.

\section{Operationalisation and calibration}

The basis for our QCA is the translation of the MSF's concepts into conditions (operationalisation) and the assignment of set membership scores to our cases for each condition (calibration). As Engler and Herweg $(2019,906)$ point out, the operationalisation of the MSF is challenging, since there are no established indicators for the framework's elements. However, existing studies that combine elements of the MSF with QCA offer hints at how to operationalise the different elements (Sager and Rielle 2013; Sager and Thomann 2017). Concerning the calibration, set membership is determined through theoretical and case-based knowledge. Here, the point of indifference (0.5) is of central importance. It determines under which circumstances a case is rather part of a subset (set value $>0.5$ ) or not (set value <0.5) (Schneider and Wagemann 2013, 32; Sager and Thomann 
Table 2. Calibration of outcome and conditions

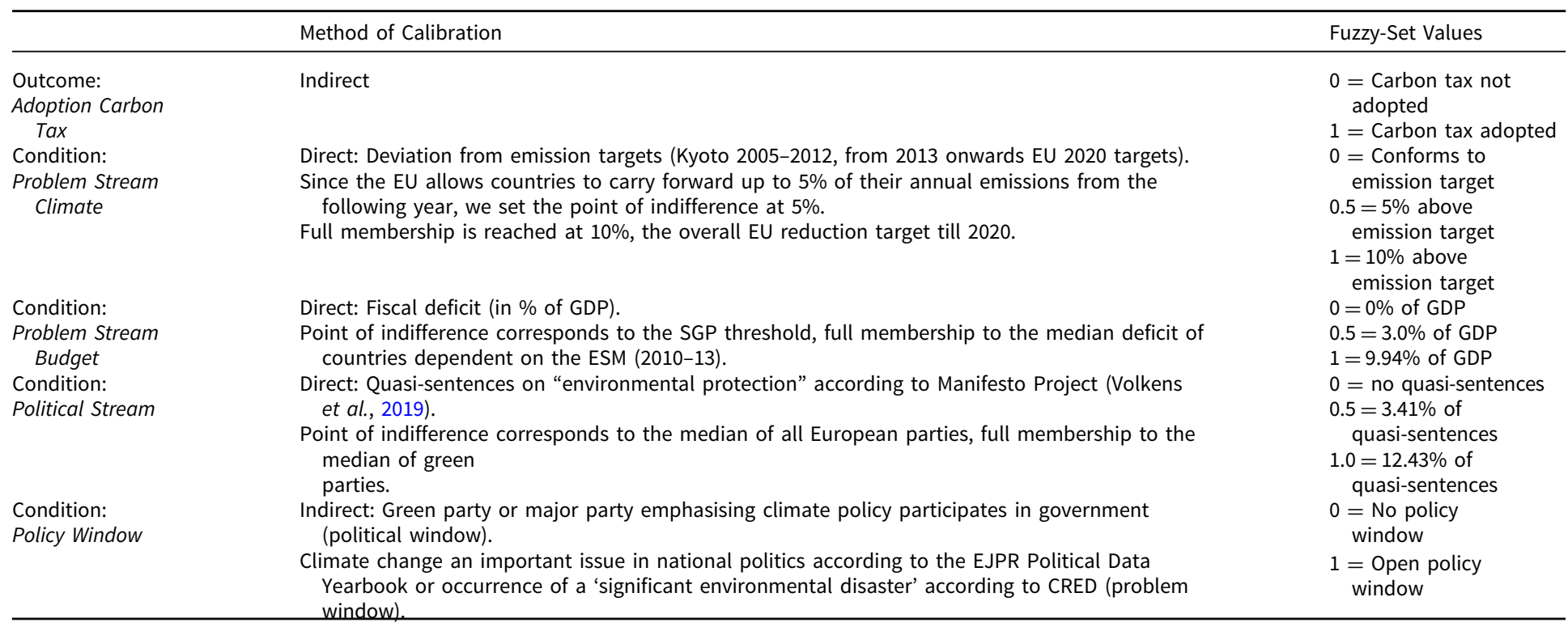

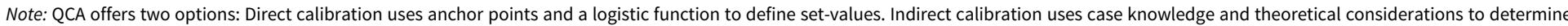
membership scores (Schneider and Wagemann 2013, 35). 
2017, 300). The operationalisation and calibration of conditions and outcomes are summarised in Table 2 and discussed in more detail in the following sections.

\section{Problem stream}

In accordance with Sager and Thomann (2017), we use quantitative indicators to determine the ripeness of the problem stream. As outlined above, the problem stream incorporates two elements, namely environmental and fiscal pressure. The environmental indicator covers the difference between the countries' $\mathrm{CO}_{2 \mathrm{e}^{-}}$ reduction targets based on the $\mathrm{EU}$ commitments and their actual $\mathrm{CO}_{2 \mathrm{e}}$-emissions, because this is the most objective measure of 'climate pressure'. ${ }^{4}$ To calibrate the environmental indicator, we refer to the EU requirements that allow countries to carry forward up to $5 \%$ of their annual emissions to the following year. Hence, we assign a membership value greater than 0.5 if the difference between emissions targets and actual emissions exceeds 5\%. A full membership (value of 1) is reached at a deviation of at least $10 \%$, the overall EU reduction target till 2020. The second indicator measures the fiscal pressure based on the countries' annual budget deficit. To decide on the urgency of budget consolidation, we refer to the European Stability and Growth Pact (SGP), which requires each member to limit the annual deficit to $3 \%$ of GDP. Therefore, countries with a deficit above this threshold receive a membership score greater than 0.5 . Full membership is reached at a deficit of $9.94 \%$, the mean deficit of countries that received support from the European Stability Mechanism during the European debt crisis.

Since legislative periods are used as units of observation, we follow Schmitt and Zohlnhöfer (2019) who point out that a government's reform agenda is substantially shaped by the problems it faces at the beginning of its term. Hence, we focus on the mean difference between the proposed and actual emissions as well as the mean budget deficits for the first half of the legislative period.

\section{Political stream}

As outlined above, our focus in the political stream is on government ideology (cf. Engler and Herweg 2019, 908; Sager and Thomann 2017). The Manifesto Project provides data on parties' emphasis on 'environmental protection', which can be used to calculate government values for this issue (Volkens et al. 2019). ${ }^{5}$ In the case of multi-party governments, parties' emphasis on environmental protection is weighted according to their share of cabinet seats. Governments with values above the median value $(3.41 \%)$ of all European parties are perceived as rather greenminded governments and thus receive a membership value greater than 0.5 . Moreover, governments with a value of at least $12.43 \%$, the median of European green parties, receive a membership value of 1 .

\section{Policy window}

In general, policy windows can open either in the problem stream (problem window) or in the political stream (political window). To determine if a problem window was available, we rely on a qualitative calibration process taking different 
sources into account (see Table A2 and Table A3 in the Appendix). First, we reviewed the relevant country reports from the Political Data Yearbook of the European Journal of Political Research to determine whether climate change was an important issue in national politics. Second, we searched the International Disaster Database for climate-change related focusing events such as heat waves, wildfires, and droughts. To qualify as a focusing event, the disasters had to be classified as "significant disasters" by the Centre for Research on the Epidemiology of Disasters (CRED n.d.). ${ }^{6}$ A problem window is supposed to be open when either climate change was an important issue in the legislative period and/or a focusing event occurred in this period.

Turning to political windows, we focus on changes in government (Engler and Herweg 2019, 909) and suggest that such windows either open when a green party participates in the government, thus increasing its impact on climate policy, or when the leaders of major parties emphasise the climate issue before forming the government. Our coding with regard to nongreen parties highlighting climate policy is again based on election reports from the Political Data Yearbook of the European Journal of Political Research (for a complete list of sources see Table A2 in the Appendix).

\section{Descriptive results}

We first provide a descriptive overview of the ripeness of the MSF's elements. We consider an element to be ripe if the set membership score is higher than 0.5 . Table 3 provides an overview of the ripeness of streams and the opening of policy windows for our six countries' 16 legislative periods. The table offers three major insights. First, and in line with the basic expectation of the MSF, a carbon tax is introduced when all elements are ready for coupling. Such a favourable situation for the introduction of carbon taxation arose in Iceland (2009-2013) and Ireland (2007-2011) when environmental and fiscal pressure coincided with green-minded governments and windows of opportunity. A carbon tax is also adopted when the problem stream is exclusively ripe due to fiscal pressure, with the other elements also ready for coupling. This is the case in the UK (2010-2015) and in France (2012-2017). Notably, the same constellation did not lead to the adoption of carbon taxation in France from 2007 to 2012.

The second finding concerns the timing of the reforms in the six countries. According to the MSF's logic, the probability of the adoption of a policy increases with the number of MSF elements ready for coupling. In our case, this logic indeed applies to four countries, as the conditions for reform became more favourable in Iceland, Ireland, France, and the UK over time. The other two countries do not fit this pattern. In Portugal and Spain, there was, based on our calibration, neither policy window nor ripe political stream but only a ripe problem stream due to fiscal pressure at the time of the adoption of the carbon tax. Since we assume the availability of a policy window to be a necessary condition for policy adoption, we will return to this surprising finding in the case study section. At this point, the Iberian cases indicate that fiscal pressure plays an important role in the introduction of carbon taxation. Notably, fiscal pressure was existent in all six countries when the carbon tax was adopted. The third finding is thus that, based on our descriptive results, 
Table 3. Overview of the MSF's elements

\begin{tabular}{|c|c|c|c|c|c|c|c|c|c|c|c|c|c|c|c|c|}
\hline & $\begin{array}{c}\text { France } \\
02-07\end{array}$ & $\begin{array}{c}\text { France } \\
07-12\end{array}$ & $\begin{array}{c}\text { France } \\
12-17\end{array}$ & $\begin{array}{l}\text { Iceland } \\
03-07\end{array}$ & $\begin{array}{l}\text { Iceland } \\
07-09\end{array}$ & $\begin{array}{c}\text { Iceland } \\
09-13\end{array}$ & $\begin{array}{l}\text { Ireland } \\
02-07\end{array}$ & $\begin{array}{l}\text { Ireland } \\
07-11\end{array}$ & $\begin{array}{c}\text { Portugal } \\
05-09\end{array}$ & $\begin{array}{c}\text { Portugal } \\
09-11\end{array}$ & $\begin{array}{c}\text { Portugal } \\
11-15\end{array}$ & $\begin{array}{l}\text { Spain } \\
04-08\end{array}$ & $\begin{array}{l}\text { Spain } \\
08-11\end{array}$ & $\begin{array}{l}\text { Spain } \\
11-15\end{array}$ & $\begin{array}{c}\text { UK } \\
05-10\end{array}$ & $\begin{array}{c}\text { UK } \\
10-15\end{array}$ \\
\hline \multicolumn{17}{|l|}{$\begin{array}{l}\text { Problem } \\
\text { Stream }\end{array}$} \\
\hline Climate & - & - & - & + & + & + & + & + & + & - & - & + & + & - & - & - \\
\hline Budget & - & + & + & - & + & + & - & + & + & + & + & - & + & + & + & + \\
\hline $\begin{array}{l}\text { Political } \\
\text { Stream }\end{array}$ & - & + & + & - & + & + & + & + & + & + & - & - & + & - & - & + \\
\hline $\begin{array}{l}\text { Policy } \\
\text { Window }\end{array}$ & - & + & + & - & - & + & - & + & - & - & - & - & - & - & - & + \\
\hline $\begin{array}{l}\text { Problem } \\
\text { Window }\end{array}$ & - & - & - & - & - & - & - & - & - & - & - & - & - & - & - & - \\
\hline $\begin{array}{l}\text { Political } \\
\text { Window }\end{array}$ & - & + & + & - & - & + & - & + & - & - & - & - & - & - & - & + \\
\hline $\begin{array}{l}\text { Policy } \\
\text { Stream }\end{array}$ & $(+)$ & $(+)$ & $(+)$ & $(+)$ & $(+)$ & $(+)$ & $(+)$ & $(+)$ & $(+)$ & $(+)$ & $(+)$ & $(+)$ & $(+)$ & $(+)$ & $(+)$ & $(+)$ \\
\hline $\begin{array}{l}\text { Ripe } \\
\text { Elements }\end{array}$ & 1 & 4 & 4 & 2 & 4 & 5 & 3 & 5 & 4 & 3 & 2 & 2 & 4 & 2 & 2 & 4 \\
\hline Outcome & 0 & 0 & 1 & 0 & 0 & 1 & 0 & 1 & 0 & 0 & 1 & 0 & 0 & 1 & 0 & 1 \\
\hline
\end{tabular}


Table 4. Sufficient solution paths

\begin{tabular}{lcccc}
\hline Solution Paths & Consistency & $\begin{array}{c}\text { PRI- } \\
\text { Value }\end{array}$ & Coverage & Cases \\
\hline $\begin{array}{l}\text { Outcome: Carbon Tax } \\
\begin{array}{l}\text { Problem-Stream Climate* Problem Stream Budget * } \\
\text { Political Stream * Policy Window }\end{array}\end{array}$ & $\mathbf{1 . 0 0}$ & $\mathbf{1 . 0 0}$ & $\mathbf{0 . 1 8}$ & $\begin{array}{c}\text { Iceland_09- } \\
\text { 13;Ireland- } \\
\text { 07-11 }\end{array}$ \\
$\begin{array}{l}\text { Overall Consistency: } 1.00 \\
\text { Overall PRI-Value: } 1.00 \\
\text { Overall Coverage: } 0.18\end{array}$ & & & & \\
\hline
\end{tabular}

Note: " " indicates the negation of a condition. "*" stands for a logical "and". "+" stands for a logical "or".

strong pressure for budget consolidation is more important than missing the climate targets, presumably because it exerts a strong reform pressure on green-minded and not so green-minded governments alike.

\section{Necessary and sufficient conditions}

In the next step, we turn to necessary and sufficient conditions using fsQCA. The measurement of consistency indicates to which degree a condition is sufficient and/ or necessary for an outcome. While the choice of an appropriate level of consistency is research specific, the literature recommends a condition to exceed the consistency level of 0.75 to be sufficient and of 0.9 to be necessary (Schneider and Wagemann 2013, 119-143; Sager and Thomann 2017, 300).

Concerning necessity, though no single condition reaches the critical consistency level of 0.9 , the condition 'budget' in the problem stream comes close with a value of 0.81 (see Table A4 in the Appendix). This is in line with our descriptive results, which show that each government that introduced a carbon tax was under fiscal pressure at that time. However, the interpretation of the result is complicated by the problem of triviality, which states that a necessary condition could be trivial if its distribution is skewed, i.e. if the condition is present or absent in too many cases of the sample (Schneider and Wagemann 2013, 236). The so-called relevance of necessity (RoN) value indicates if this is the case. Following Schneider (2018, 250251 ) in suggesting that only conditions above a RoN value of 0.5 are not trivial, we see that the condition "budget" $(\mathrm{RoN}=0.59)$ narrowly passes the threshold. One reason for the skewness of the condition is the global financial crisis starting in 2007. Based on our results, we cannot conclusively answer the question if fiscal pressure was indeed necessary for the adoption of carbon taxation. The subsequent case studies will offer more evidence on the impact of deteriorating public finances on the adoption of carbon taxation.

The analysis of sufficiency provides one solution path, which covers the Irish as well as the Icelandic case (see Table 4 ). ${ }^{7}$ The solution path shows that only the combination of all four elements is sufficient for the adoption of carbon taxation, i.e. only the interplay of fiscal and environmental pressure, favourable political conditions, and the openness of a policy window definitely leads to this outcome. This result is in line with our expectation that policy adoption is most likely when the streams are ripe and a policy window is available. As expected, every other 
constellation is not sufficient for the adoption of a carbon tax, though the tax may nevertheless be introduced under less favourable conditions as the descriptive results show.

\section{Case studies}

While the QCA allows us to discern crosscase patterns, it tells us nothing about the "causal quality of the solutions and its constitutive terms [and] the underlying causal mechanisms" (Schneider and Rohlfing 2016, 526), especially the coupling efforts by potential policy entrepreneurs under changing conditions. Hence, we supplement the QCA with two case studies. First, we take a closer look at Ireland, one of the two members of the solution path and thus as typical case for sufficiency. In this case, our results suggest that conditions for policy entrepreneurs in support of carbon taxation have improved over time and thus facilitated the coupling of the streams. Next, we turn to Portugal to investigate which role agency played in a case in which carbon taxation was introduced at a time when the conditions for coupling the streams appeared highly unfavourable, not least due to the alleged absence of a policy window.

\section{Ireland}

The Irish case covers two legislative periods with different outcomes. After the carbon tax had been on the agenda but was ultimately postponed in the first period from 2002 to 2007, it was adopted after the change of government following the 2007 election. According to our findings presented in Table 3, changes in the problem stream (fiscal pressure) as well as the opening of a policy window should be responsible for the different outcomes.

The first legislative period was marked by mixed signals in the problem stream. The environmental pressure was substantial, as the Environmental Protection Agency estimated that Ireland would overshoot its emission targets by about $25 \%$ and called for urgent emission reductions (EPA 2004). Consequently, the Minister for the Environment, Martin Cullen (Fianna Fáil), proposed carbon taxation as an instrument to reduce emissions and avert fines of $€ 1.3$ billion for breaching the Kyoto Protocol (Coghlan 2007, 147). The main advocate of the carbon tax was, however, Noel Dempsey (Fianna Fáil) who had negotiated Ireland's emission targets at the Kyoto conference and now served as Minister for Communications, the Marine and Natural Resources. Dempsey had developed the government's climate policy agenda and pushed for domestic measures such as carbon taxation (Coghlan 2007, 138-141). Driven by "an inclination to 'do the right thing", Dempsey pursued his goal with a "focus on policy detail" as well as "stubbornness" (Little 2017, 206). Backed by Dempsey and the epistemic community, amongst others economists from the OECD and the domestic Economic and Social Research Institute (Stapleton et al. 2006; Coghlan 2007, 148), the carbon tax became part of the budget plan presented at the beginning of the legislative period (Government of Ireland 2002). In sum, there was substantial environmental pressure to act, a policy community supportive of a carbon tax, and policy entrepreneurs within the government. 
So why did the reform initiative for a carbon tax nevertheless fail? The answer to this question can be found in the problem stream as well as in the political stream. Fiscal pressure, the most important factor according to the QCA, was nonexistent as the Irish government was presiding over budget surpluses from 2003 to 2007. Based on interviews, Clinch and Dunne $(2006,958)$ conclude that "at the height of Ireland's economic boom when exchequer receipts were at an all-time high, the revenues from environmental taxes were of very limited interest to Irish officials“. In the political stream, Dempsey and Cullen faced substantial resistance not only from the junior partner in the coalition, the Progressive Democrats (PD), but also from their own party. The PD-led Department of Enterprise sided with the Irish Business and Employers Confederation which opposed the new tax fearing for Ireland's international competitiveness (Little 2017, 206). Against this background of departmental disunity, Finance Minister Charlie McCreevy (Fianna Fáil) held an important position in the policy process. Without the urgency to generate additional revenues, McCreevy first postponed the carbon tax by consulting the social partners and, sensing resistance by employers and unions alike, abandoned it altogether in September 2004. The decision was made at a time of rising oil and gas prices and thus justified on grounds of fighting inflation (Coghlan 2007, 141-150; Little 2017, 205-209). To sum up, the initiative for carbon taxation failed due to Ireland's economic boom, which eased fiscal pressure and fuelled inflation, and formidable resistance by influential actors inside and outside of the government.

The adoption of a carbon tax in December 2009, the midst of the subsequent legislative period, was preceded by two significant changes, one occurring in the political stream, the other in the problem stream. The former change resulted from the 2007 election, after which the Green Party joined the governing coalition. This clearly created a policy window as the Green Party was willing to use its political capital to push for the carbon tax of $€ 20 / \mathrm{tCO}_{2}$ promised in its election manifesto (Green Party 2007, 10-11). As a result, the proposal was not only included in the government program but also subsequently kept alive by the Greens. Most importantly, when another endless delay of the tax loomed in 2009, party leader and environment minister John Gormley acted as policy entrepreneur. In the wake of severe losses in the 2009 local elections, the Green Party's leadership made clear that the party would leave the government if there would not be "green fingerprints all over the renegotiated government program" (Brennan 2009). Thus pressured by the Greens, Fianna Fáil finally gave in and the carbon tax was included in the renewed government program and approved by parliament in December 2009 (Government of Ireland 2009, 4; Convery et al. 2013, 11).

In the meantime, the problem stream also had altered substantially in 2008 when the global financial crisis had hit Ireland with full force, resulting in enormous fiscal pressure. The recession and rescue packages for collapsing private banks had turned budget surpluses into massive deficits of 7\% of GDP in 2008 and almost 14\% of GDP in 2009, with worse to come in the following years (OECD 2009). Under those dire fiscal circumstances, austerity measures including spending cuts and tax increases were seen as inevitable by the government to restore public finances (Government of Ireland 2008). As part of the 2010 budget, the carbon tax offered a small but substantial amount of the $€ 4$ billion in savings of "the most austere Budget in the history of the State" (McGee 2009). To put this into perspective, 
the $€ 246$ million raised by the carbon tax amounted to about $25 \%$ of total tax increases (Convery et al. 2013, 13-16). While the tax meant increased costs of living for most households and was thus far from popular, it could at least be justified on environmental grounds.

In sum, the Irish case demonstrates how rising problem pressure due to deteriorating public finances and government participation of the Greens facilitated the coupling efforts of policy entrepreneurs and thus paved the way for policy adoption. Notably, urgent fiscal pressure proved more important in this regard than latent environmental pressure.

\section{Portugal}

The Portuguese case covers three legislative periods, with two socialist governments (2005-2009, 2009-2011) followed by a conservative government in 2011. Based on our previous findings, the introduction of carbon taxation in 2014 is quite surprising, since the conditions for a carbon tax appear to have deteriorated over time (see Table 3). However, a closer look at the Portuguese case reveals that a policy window opened in the political stream during the third legislative period which led to the adoption of carbon taxation.

At first sight, conditions for the adoption of a carbon tax seemed promising after the 2005 election. In the election campaign, the Socialist Party (PS) put a stronger emphasis on environmental issues than their main right-wing opponents, though a carbon tax was missing in the former's manifesto (PS 2005). In addition, green taxes presented one option to deal with the budget deficit, which exceeded the SGP threshold of $3 \%$. In fact, a carbon tax was mentioned in the government's 'Grand Option Plan 2005-2009' (Lei 52/2005) approved by parliament in August 2005. However, the complete disappearance of the carbon tax from the governmental agenda in the subsequent years indicates that the PS did not act out of conviction but merely reacted to external pressure from the EU (Carvalho et al. 2014, 203-207). Crucially, a national policy entrepreneur who could have capitalised on the rather favourable conditions was missing.

After the 2011 election, the Socialist government was replaced by a coalition of two center-right parties, the Social Democratic Party (PSD) and the People's Party (CDS-PP). In line with our QCA, this change of government negatively affected the political stream, leading to "a significant restructuring of the Ministry of the Environment, a reduction in government agencies and the downgrading of environmental issues in general and climate change in particular in government priorities" (Carvalho et al. 2014, 206). In the election campaign, the introduction of a carbon tax was neither proposed by the PSD nor by the People's Party to contribute to the fiscal consolidation demanded by the Troika (CDS-PP 2011; PSD 2011). Developments in the problem stream may have contributed to this reluctance. The economic crisis led to massive budget deficits but at the same time reduced industrial production and thus carbon emissions. Consequently, fighting climate change was not at the top of the public agenda: "In 2011, 75\% [of Portuguese respondents in the Eurobarometer] considered climate change a very serious problem. [...] However [...] only $7 \%[\ldots]$ chose climate change (against $20 \%$ of Europeans) as the most serious problem" (Carvalho et al. 2014, 207-208). 
Unsurprisingly, the economic crisis was the main concern of Portuguese respondents. Finally, neither the problem stream nor the political stream provided potential policy entrepreneurs with a policy window in 2011.

However, things changed abruptly in July 2013, when Prime Minister Pedro Passos Coelho reshuffled the cabinet to avert the collapse of the coalition (Magone 2014). The government crisis was sparked by the resignation of Finance Minister Vítor Gaspar as a reaction to a negative ruling by the Constitutional Court against some of Gaspar's austerity measures. Passos Coelho's appointment of Maria Luis Albuquerque as new Finance Minister without consultation of the People's Party led to a deep government crisis which was solved by a cabinet reshuffle. In the context of our analysis, the crucial change concerned the Ministry of Environment: "The quite large ministry of Agriculture, Sea, Environment and Planning of Territory was [...] split into two. The existing minister, Assunção Cristas, was appointed head of the new Ministry of Agriculture and Sea, and newly appointed Jorge Moreira da Silva was placed in charge of the new Ministry of Environment, Territorial Planning and Energy" (Magone 2014, 259).

The appointment of Moreira da Silva proved crucial as he was not only an influential figure within the PSD but also "the man of renewable energies and the carbon tax" (Ferreira 2013). In terms of the MSF, Moreira da Silva comes close to the ideal policy entrepreneur (cf. Kingdon 1995, 179-183), combining political influence as minister and the PSD's vice president with an academic background and a clear policy agenda on fighting climate change. Having been an "important policy entrepreneur [who] displayed a capacity to build alliances and to put together a crossparty consensus, covering both progressive-environmentalist and conservative probusiness fractions" (Braun 2009, 483) when serving as rapporteur in the European Parliament during the creation of the EU ETS, Moreira da Silva founded the Lisbonbased think tank "Platform for a Sustainable Growth" in 2011. A report published by the think tank in December 2012 recommended "[r]eplacing the possible extension to 2014 of the $3.5 \%$ surcharge on Individual Income Tax applied in 2013 by introducing a carbon tax of $€ 9.00$ per ton of $\mathrm{CO} 2$, discouraging national greenhouse gas emissions and inducing more sustainable production and consumption standards" (Moreira da Silva 2012, 17). As early as August 2011, Moreira da Silva publicly spoke out in favour of a carbon tax instead of raising income taxes (Alvarez 2011).

In terms of the MSF, Moreira da Silva's promotion opened a policy window in the political stream. Based on the powerful environment minister's initiative, a commission on green tax reform (reforma fiscalidade verde) was established in early 2014. In September 2014, the commission published its final report, amongst others proposing a carbon tax along the lines of Moreira da Silva's previous recommendations (Comissão Fiscalidade Verde 2014, 65-93). Notably, the carbon tax and additional green taxes were presented as a way to reduce taxes on labour income which had risen during the fiscal crisis (Portuguese Ministry of Environment 2014, 2-4). The carbon tax was approved by parliament in November 2014 as part of the green tax reform and introduced in 2015. In short, Moreira da Silva, after profiting from a government crisis triggered by fiscal pressure, served as an extremely influential policy entrepreneur who skillfully coupled the three streams to further green tax reform including carbon taxation. Crucially and in contrast 
to our theoretical assumptions, it was not a change in government but a cabinet reshuffle which opened the policy window in the middle of the legislative period.

\section{Conclusion}

In this article, we applied the MSF to analyse the timing of the adoption of carbon taxation in advanced democracies. The article focused on six Western European countries which introduced carbon taxation after 2008 when carbon pricing had already become a global norm and countries faced internationally binding emission reduction targets. Our analysis proceeded in two steps. In the first step, we conducted a QCA to identify conditions favourable to the introduction of carbon taxation. This yielded two major results. First, the QCA confirms previous findings that fiscal crises provide favourable conditions for the adoption of carbon taxes (e.g. Sterner 1994; Harrison 2010; Speck 2013; Skovgaard et al. 2019). According to our results, heightened fiscal pressure may even have been a necessary condition for policy adoption in our six countries. However, fiscal pressure is not sufficient for this outcome. Thus, our second finding is that the introduction of carbon taxation becomes most likely when high fiscal pressure coincides with governments receptive to environmental issues, e.g. when greens parties are part of the government. In other words, the conjunction of push and pull factors provides a fertile ground for policy adoption.

In the second step, we added two additional case studies on Ireland and Portugal to illuminate the actual reform process, especially the role of policy entrepreneurs. In the Irish case, policy entrepreneurs profited, as indicated by the previous analysis, from changing context conditions, especially heightened fiscal pressure and the Greens entering the government. The Portuguese case offered a more puzzling picture, since there appeared to be no policy window available at the time of policy adoption. Here, the case study showed that reform conditions were indeed unfavourable at the beginning of the 2011-2015 legislative period. In contrast to our expectations, it was not a change in government but a cabinet reshuffle during the legislative period which opened a policy window in the political stream. Moreover, the Portuguese case highlights the importance of a strong policy entrepreneur for coupling the streams. In contrast to the early phases of the Irish case, where policy entrepreneurs possessed ideological conviction but lacked political assertiveness, the Portuguese policy entrepreneur, Moreira da Silva, combined both. In line with findings from welfare state research, it is exactly this kind of minister that is able to affect the government's policy agenda (cf. Alexiadou 2015).

To what extent will these findings apply to other parts of the world? Research on carbon pricing indicates that conditions in Western Europe are generally more favourable to the introduction of carbon taxes than in less affluent regions such as Southeast Asia and South America (Skovgaard et al. 2019; Thisted and Thisted 2019). Nevertheless, research also indicates that some of our findings can be applied to those regions. As global studies demonstrate, the impact of fiscal and economic crises on the adoption of carbon taxation is not restricted to Europe (Skovgaard et al. 2019; Steinebach et al., 2021). On the country level, this is confirmed by a recent study on Argentina which demonstrates that fiscal and economic 
considerations indeed played an important role for the adoption of carbon taxation (Ryan and Micozzi 2021). However, since green parties generally play no major role in developing countries (cf. Skovgaard et al. 2019, 1178), other political actors, such as influential political entrepreneurs inside the government, are needed to overcome the opposition to carbon pricing (Dyarto and Setyawan 2020; Ryan and Micozzi 2021). Finally, the international awareness of the necessity for stronger climate policies is still rising which is why initiatives for carbon taxes are supposed to be more and more driven by environmental considerations in the future.

Moving beyond climate policy, our study demonstrates that the combination of MSF and QCA can help to better understand the timing of reforms across countries. At the same time, the study highlights two methodological issues. First, not all elements of the MSF, such as the policy entrepreneur, can easily be translated into QCA conditions when covering more than a small number of cases. One solution to this problem is the partial application of the MSF (cf. Engler and Herweg 2019). Another solution, chosen in this study, is to complement the MSF's partial application in the QCA with case studies including all elements. Thus, the QCA can be employed to analyse the conditions for policy adoption, while the case studies can illuminate the actual coupling activities by potential policy entrepreneurs in the reform process. Second, researchers may face practical trade-offs when defining the unit of analysis. One the one hand, governments' legislative periods present a convenient unit in terms of the political stream. On the other hand, sudden cabinet reshuffles during the legislative period, as seen in the Portuguese case, can change the dynamic in the political stream and even open a policy window (cf. Kingdon 1995, 174-175). Dealing with a medium or large number of governments, such momentous personnel turnover is however hard to determine for each case beforehand. Notwithstanding those methodological challenges, the combination of MSF and QCA promises insights on crosscountry reform patterns not accessible through other approaches. The MSF offers the theoretical framework to capture the interplay of various structural and political factors, while QCA presents the fitting method to grapple with conjunctural causality. Complemented by well-selected case studies, this approach can thus be of use to public policy scholars in various policy fields.

Supplementary material. For supplementary material accompanying this paper visit https://doi.org/10. $1017 /$ S0143814X21000210

Acknowledgements. The article benefited substantially from the help of Lea Maurer. We also thank the two anonymous reviewers for their helpful suggestions and remarks.

Data availability statement. Replication materials are available in the Journal of Public Policy Dataverse at: https://doi.org/10.7910/DVN/V6MOYT.

\section{Notes}

1. Other relevant factors such as electoral systems and neo-corporatist structures are rather static and thus better suited to explain cross-country differences than the timing of policy adoptions.

2. These taxes differ in the carbon price level and in the share of covered emissions but their designs are, with the exception of the UK, quite similar. Iceland, Ireland, France and Portugal raise a tax on fossil fuels based on potential $\mathrm{CO}_{2}$ emissions. The Spanish carbon tax does not put a price on $\mathrm{CO}_{2}$ emissions but on emissions from fluorinated greenhouse gases (HFCs, PFCs, and SF6) (World Bank 2020), which explains 
why the share of covered emissions is rather low. In contrast, the British scheme is based upon a so-called price floor. It tops up the allowance price of the EU ETS to reach a price level requested by the government (Hirst 2018). The price floor provides firms under the EU ETS with a stable and predictable carbon price and thus acts like a carbon tax.

3. Note that QCA follows a deterministic logic, whereas the MSF's logic is probabilistic. Though this methodological problem cannot be solved completely, we are able to "mitigate the difference between the MSF's and QCA's logic of causality by including measures in QCA that indicate the consistency of the empirical evidence with the theoretically established statements on sufficient and necessary conditions" (Engler and Herweg 2019, 913; see also Schneider and Wagemann 2013, 316-317).

4. Polling data offer an alternative, more perception-based way to measure 'environmental pressure'. However, survey data from the Eurobarometer, the European Election Studies and the Comparative Study of Electoral Systems are not only patchy but often inconsistent (see Appendix, Tab. A1).

5. We use the 'environmental protection' item of the Manifesto Project ("General policies in favor of protecting the environment, fighting climate change, and other "green" policies"). The indicator provides the quasi-sentences in the respective category as a share of the total number of assigned codes within an election program (Volkens et al. 2019).

6. 'Significant disasters' are disasters that either resulted in the declaration of the state of emergency or are classified as "worst disaster of the decade" and/or "disaster with the greatest damage to the country" by the CRED (n.d.). Though such 'significant disasters' occurred in some of the six covered countries since 2000, none of those disasters occurred in the period covered in our analysis (see Table A3 in the Appendix).

7. Note, that we present the complex solution, which is not based on simplifying assumptions about logical remainders (cf. Schneider and Wagemann 2010). The truth table, the results of the intermediate and the parsimonious solution as well as robustness checks are presented and discussed in the Appendix (see Tab. A5-A10).

\section{References}

Alexiadou D (2015) Ideologues, Partisans, and Loyalists: Cabinet Ministers and Social Welfare Reform in Parliamentary Democracies. Comparative Political Studies, 48(8): 1051-1086.

Alvarez L (2011) Vice-presidente do PSD quer imposto sobre poluidores para aliviar carga fiscal sobre o trabalho. Público, https://www.publico.pt/2011/08/30/politica/noticia/vicepresidente-do-psd-querimposto-sobre-poluidores-para-aliviar-carga-fiscal-sobre-o-trabalho-1509778 (accessed 05 January 2020).

Andersen MS (2009) Carbon-Energy Taxation: Lessons from Europe. Oxford: Oxford University Press.

Andersen MS (2019) The Politics of Carbon Taxation: How Varieties of Policy Style Matter. Environmental Politics, 28(6): 1084-1104.

Beach D and Rohlfing I (2018) Integrating Cross-Case Analyses and Process Tracing in Set-Theoretic Research: Strategies and Parameters of Debate. Sociological Methods \& Research, 47(1): 3-36.

Blatter J and Haverland M (2012) Designing Case Studies: Explanatory Approaches in Small-N Research. London: Palgrave Macmillan.

Braun M (2009) The Evolution of Emissions Trading in the European Union: The Role of Policy Networks, Knowledge and Policy Entrepreneurs. Accounting, Organizations and Society, 34(3-4): 469-487.

Brennan M (2009) Greens Put Coalition on Line Over Fuel Taxes. Independent.ie, https://www. independent.ie/irish-news/greens-put-coalition-on-line-over-fuel-taxes-26552246.html (accessed 05 January 2020).

Carvalho A, Schmidt L, Santos, FD and Delicado A (2014) Climate Change Research and Policy in Portugal. WIREs Climate Change, 5(2): 199-217.

CDS-PP (2011). Este é o momento. Manifesto Eleitoral 2011. Por ti. Por todos. Portugal. Lisbon: CDS People's Party.

Clinch JP and Dunne L (2006) Environmental Tax Reform: An Assessment of Social Responses in Ireland. Energy Policy, 34(8): 950-959.

Coghlan O (2007) Irish Climate-Change Policy from Kyoto to the Carbon Tax: A Two-Level Game Analysis of the Interplay of Knowledge and Power. Irish Studies in International Affairs, 18: 131-153.

Comissão Fiscalidade Verde (2014) Projeto de Reforma da Fiscalidade Verde. Lisbon. 
Convery FJ (2009) Origins and development of the EU ETS. Environmental and Resource Economics 43(3): 391-412.

Convery FJ, Dunne L and Joyce D (2013) Ireland's carbon tax and the fiscal crisis. OECD Environment Working Papers, no. 59. Paris: OECD.

Cooper-Searle S, Livesey F and Allwood JM (2018) Why Are Material Efficiency Solutions a Limited Part of the Climate Policy Agenda? An Application of the Multiple Streams Framework to UK Policy on $\mathrm{CO}_{2}$ Emissions from Cars. Environmental Policy and Governance, 28(1): 51-64.

CRED (n.d.) Guidelines, https://www.emdat.be/guidelines (accessed 11 June 2021).

Dyarto R and Setyawan D (2020) Understanding the Political Challenges of Introducing a Carbon Tax in Indonesia. International Journal of Environmental Science and Technology, 18(6): 1479-1488.

Engler F and Herweg N (2019) Of Barriers to Entry for Medium and Large N Multiple Streams Applications: Methodological and Conceptual Considerations. Policy Studies Journal, 47(4): 905-926.

EPA (2004) Ireland's Environment 2004. Dublin: Environmental Protection Agency.

Ferreira L (2013) Jorge Moreira da Silva Chegar ao Governo após duas falsas partidas. Público, https://www. publico.pt/2013/07/24/jornal/jorge-moreira-da-silva-chegar-ao-governo-apos-duas-falsas-partidas-26867874 (accessed 05 January 2020).

Government of Ireland (2002) Financial Statement of the Minister for Finance Mr. Charlie McCreevy, 4 December 2002, http://www.budget.gov.ie/Budgets/2003/FinancialStatement.aspx\#Energytax (accessed 05 January 2020).

Government of Ireland (2008) Financial Statement of the Minister for Finance Mr Brian Lenihan, 14 October 2008, http://www.budget.gov.ie/Budgets/2009/FinancialStatement.aspx (accessed 05 January 2020).

Government of Ireland (2009) Proposed Renewed Programme for Government, 10 October 2009, https:// www.socialjustice.ie/system/files/file-uploads/2021-09/2009-10-10-renewedprogrammeforgovernment1. pdf (accessed 09 December 2021).

Green Party (2007) Manifesto 2007: It's Time. Dublin: Green Party.

Haites E (2018) Carbon Taxes and Greenhouse Gas Emissions Trading Systems: What Have We Learned? Climate Policy, 18(8): 955-966.

Harrison K (2010) The Comparative Politics of Carbon Taxation. Annual Review of Law and Social Science, 6(1): 507-529.

Herweg N, Huß C and Zohlnhöfer R (2015) Straightening the Three Streams: Theorising Extensions of the Multiple Streams Framework. European Journal of Political Research, 54(3): 435-449.

Herweg N, Zahariadis N and Zohlnhöfer R (2018) The Multiple Streams Framework: Foundations, Refinements, and Empirical Applications. In Weible C. M. and Sabatier P. A. (eds.), Theories of the Policy Process. New York: Routledge, 17-53.

Hirst D (2018) Carbon Price Floor (CPF) and the Price Support Mechanism. London: House of Commons Library.

Jagers SC and Hammar H (2009) Environmental Taxation for Good and for Bad: The Efficiency and Legitimacy of Sweden's Carbon Tax. Environmental Politics, 18(2): 218-237.

Kasa S (2000) Policy Networks as Barriers to Green Tax Reform: The Case of CO2-Taxes in Norway. Environmental Politics, 9(4): 104-122.

Keskitalo E, Carina H, Westerhoff L and Juhola S (2012) Agenda-setting on the environment: the development of climate change adaptation as an issue in European states. Environmental Policy and Governance, 22(6): 381-394.

Kingdon JW (1995) Agendas, Alternatives, and Public Policies. New York: Longman.

Little C (2017) Intra-party policy entrepreneurship and party goals: the case of political parties' climate policy preferences in Ireland. Irish Political Studies, 32(2): 199-223.

Magone JM (2014) Portugal. European Journal of Political Research Political Data Yearbook, 53(1): 257264.

McGee H (2009) Few surprises in much-leaked budget. The Irish Times, https://www.irishtimes.com/news/ few-surprises-in-much-leaked-budget-1.850397 (accessed 06 January 2020).

Moreira da Silva J (2012) Report for sustainable growth: a post-troika strategy for Portugal. Lisbon: Platform for Sustainable Growth.

OECD (2009) OECD Economic Surveys: Ireland 2009. Paris: OECD.

Padilla E and Roca J (2004) The Proposals for a European Tax on CO2 and Their Implications for Intercountry Distribution. Environmental and Resource Economics, 27(3): 273-295. 
Portuguese Ministry of Environment (2014) Green Taxation Reform: Taxing More of What We Burn and Less of What We Earn. Lisbon: Portuguese Government.

PS (2005) Bases progamáticas: legislativas 2005. Lisbon: Partido Socialista.

PSD (2011) Recuperar a credibilidade e desenvolver Portugal: programa eleitoral do Partido Social Democrata eleições legislativas 2011. Lisbon: Partido Social Democrata.

Rabe BG (2018) Can We Price Carbon? American and Comparative Environmental Policy. Cambridge: The MIT Press.

Ragin CC (2008) The Comparative Method: Moving Beyond Qualitative and Quantitative Strategies. Berkeley: University of California Press.

Ryan D and Micozzi M (2021) The Politics of Climate Policy Innovation: The Case of the Argentine Carbon Tax. Environmental Politics. Doi: 10.1080/09644016.2021.1899648.

Sager F and Rielle Y (2013) Sorting Through the Garbage Can: Under What Conditions do Governments Adopt Policy Programs? Policy Sciences, 46(1): 1-21.

Sager F and Thomann E (2017) Multiple Streams in Member State Implementation: Politics, Problem Construction and Policy Paths in Swiss Asylum Policy. Journal of Public Policy, 37(3): 287-314.

Sairinen R (2003) The Politics of Regulatory Reform: 'New' Environmental Policy Instruments in Finland. Environmental Politics, 12(1): 73-92.

Schlegelmilch K and Joas A (2016) Fiscal Considerations in the Design of Green Tax Reforms. The International Journal on Green Growth and Development, 2(2): 189-206.

Schmitt C and Zohlnhöfer R (2019) Partisan Differences and the Interventionist State in Advanced Democracies. Socio-Economic Review, 17(4): 969-992.

Schneider CQ (2018) Realists and Idealists in QCA. Political Analysis, 26(2): 246-254.

Schneider CQ and Rohlfing I (2016) Case Studies Nested in Fuzzy-Set QCA on Sufficiency. Sociological Methods \& Research, 45(3): 526-568.

Schneider CQ and Wagemann C (2010) Standards of Good Practice in Qualitative Comparative Analysis (QCA) and Fuzzy-Sets. Comparative Sociology, 9(3): 397-418.

Schneider CQ and Wagemann C (2013) Set-Theoretic Methods for the Social Sciences: A Guide to Qualitative Comparative Analysis. Cambridge: Cambridge University Press.

Sénit CA (2012) The Politics of Carbon Taxation in France: Preferences, Institutions, and Ideologies. IDDRI Working Paper, (no. 20).

Skovgaard J, Ferrari SS and Knaggård Å (2019) Mapping and Clustering the Adoption of Carbon Pricing Policies: What Polities Price Carbon and Why? Climate Policy, 19(9): 1173-1185.

Speck S (2013) Carbon Taxation: Two Decades of Experience and Future Prospects. Carbon Management, 4(2): 171-183.

Stapleton M, Lenihan H, Killian S, O'Sullivan B and Business K (2006) The Irish Carbon Tax: A Lost Opportunity? Social Responsibility Journal, 2(1): 23-34.

Steinebach Y, Fernández-i-Marín X and Aschenbrenner C (2021) Who Puts a Price on Carbon, Why and How? A Global Empirical Analysis of Carbon Pricing Policies. Climate Policy, 21(3): 277-289.

Sterner T (1994) Environmental Tax Reform: The Swedish Experience. European Environment, 4(6): 20-25.

Thisted EV and Thisted RV (2019) The Diffusion of Carbon Taxes and Emission Trading Schemes: The Emerging Norm of Carbon Pricing. Environmental Politics, 8(4): 1-21.

Volkens A, Krause W, Lehmann P, Matthieß T, Merz N, Regel S and Weßels B (2019) Manifesto Project Dataset [dataset], https://doi.org/10.25522/manifesto.mpds.2019b (accessed 01 July 2020).

World Bank (2019) State and Trends of Carbon Pricing 2019. Washington, DC: World Bank.

World Bank (2020) Carbon Pricing Dashboard, https://carbonpricingdashboard.worldbank.org/map_data (accessed 22 June 2020).

Zahariadis N (2003) Ambiguity \& Choice in Public Policy: Political Decisionmaking in Modern Democracies. Washington, DC: Georgetown University Press.

Cite this article: Bothner F, Schrader SM, Bandau F, and Holzhauser N (2022). Never let a serious crisis go to waste: the introduction of supplemental carbon taxes in Europe. Journal of Public Policy 42, 343-363. https://doi.org/10.1017/S0143814X21000210 